\title{
GESTATIONAL DIABETES MELLITUS IN PRIMIGRAVIDAE: A MILD DISEASE
}

\author{
Nor Azlin Mohamed Ismail ${ }^{1}$, Norkhatijah Mohd Aris ${ }^{2}$, Zaleha Abdullah Mahdy ${ }^{1}$, Shuhaila Ahmad, \\ Norzilawati Mohd Naim ${ }^{1}$, Harlina Harlizah Hj Siraj', Syed Zulkifli Syed Zakaria ${ }^{2}$
}

Universiti Kebangsaan Malaysia, Faculty of Medicine, Kuala Lumpur, Malaysia: Department of Obstetrics \& Gynaecology ${ }^{1}$, UKM Medical Molecular Biology Institute ${ }^{2}$

\begin{abstract}
Summary: This prospective observational study was done to analyse the prevalence of gestational diabetes mellitus (GDM) among primigravidae and its outcome. All healthy primigravidae with singleton pregnancies were offered universal glucose tolerance testing between 16 and 28 weeks gestation. GDM and non GDM groups were managed according to hospital protocol. The antenatal features and pregnancy outcomes were analysed. Out of 616 primigravidae, 113 (18.34 \%) were GDM with slightly older $(27.9 \pm 4.2$ versus $26.32 \pm 3.3$, p < 0.001$)$ age. The mean fasting and two hours postprandial blood glucose in both groups were $4.99 \pm 1.08 \mathrm{mmol} / 1,8.86 \pm 1.41 \mathrm{mmol} / 1(\mathrm{GDM})$ and $4.36 \pm 0.43 \mathrm{mmol} / 1,5.71 \pm 1.11 \mathrm{mmol} / 1$ (Non GDM), respectively. Maternal family history of diabetes mellitus, weight exceeding $80 \mathrm{Kg}$, polyhydramnios (2.65\% versus $0.2 \%, \mathrm{p}=0.028)$ and neonatal hyperbilirubinaemia ( $9.73 \%$ versus $2.98 \%, \mathrm{p}=0.01)$ occurred significantly more frequent in the GDM group compared to normal. There was no significant difference in other pregnancy outcomes and complications between the two groups. In conclusion GDM in primigravidae was detected at a relatively young age with more frequent maternal family history of DM, weight exceeding $80 \mathrm{Kg}$, polyhydromnions and neonatal hyperbilirubinaemia. The degree of disease was mild and treatment led to no significant complication.
\end{abstract}

Key words: Gestational diabetes mellitus; Primigravidae; Macrosomia; Risk factors; Polyhydramnios

\section{Introduction}

Gestational diabetes mellitus (GDM) is defined as carbohydrate intolerance of varying degrees of severity with first onset or recognition during pregnancy. It has been reported that the incidence is approximately between 1-14\% (3) of all pregnancies although in actual fact a higher incidence was found in some countries with Asian ethnicity $(19,2)$. The prevalence of GDM was also shown to be increased in other parts of the world (7). GDM has known association with maternal and perinatal complications such as pre-eclampsia and macrosomia (12). Concern extends beyond these as GDM is a mirror to the development of Type 2 diabetes mellitus (9) in later life. Prompt diagnosis of GDM in pregnant women, education on the disease process and healthy lifestyle may delay possible complications. Although policy and methods of screening for GDM varies from one centre to another, most parts of the world now have screening tests to detect GDM. There is, as yet, no consensus on the ideal way (16) of screening hence this follows the preference of the obstetrician.

Among risk factors that are known to contribute to GDM are ethnicity, history of previous GDM and obesity.
In countries with multiethnicity the prevalence may vary according to diffent ethnic groups. Several studies (2) advocated using a combination of serum fructosamine and glycated haemoglobin on a single fasting level for screening in countries with multiethnic and high risk populations. South East Asian women have an eight-fold preponderance to develop GDM compared to Caucasian women (6). The current study was done to analyse the prevalence of primigravidae alone with gestational diabetes mellitus and its outcome in our centre using the universal approach of screening.

\section{Materials and methods}

All primigravidae without medical problems, multiple pregnancies and regardless of risk to develop GDM, attending routine antenatal clinic between 2007 and 2008 were invited to enroll into the study. This prospective observational study done in a teaching hospital involved 616 primigravidae who were not known to be diabetic before. The patients' history and examination findings were recorded. Other antenatal screening tests such as blood group and infective screening were carried out as per hospital pro- 
tocol. Following 72 hours of unrestricted carbohydrate intake and at least 8 hours overnight fast, the women were subjected to a glucose tolerance test (GTT). The test was performed between 16 and 28 weeks gestation using $75 \mathrm{~g}$ oral glucose dissolved in $250 \mathrm{ml}$ water. Venous blood samples were taken at 0 hour (fasting blood glucose, FBG) and two hours post prandial (2HPPBG). The test was considered abnormal if FBG $>110 \mathrm{mg} / \mathrm{dL}(6.0 \mathrm{mmol} / \mathrm{L})$ and/or $2 \mathrm{HPPBG}>140 \mathrm{mg} / \mathrm{dL}(7.8 \mathrm{mmol} / \mathrm{L})$, indicative of GDM.

Once diagnosed to have abnormal GTT, they were treated according to the usual hospital protocol which includes diet therapy and insulin treatment (if required) with a combined obstetrician-endocrinologist team managing the patients. Maternal and fetal monitoring were done as usual and the outcome of pregnancy and delivery were compared between the GDM group and those with normal GTT. All subjects were informed of the research procedure and signed the written informed consent. This study was performed according to the Declaration of Helsinki and approved by our Institutional Research Ethics Board.

Risk factors for GDM, antenatal features, delivery outcome and neonatal parameters were analysed using SPSS 12.0. The chi-square, student t-test and Fisher exact tests and one-way analysis of variance were used for normally distributed data. Mann-Whitney $U$ and Kruskal-Wallis tests were used for non-parametric data. The test was considered significant if $\mathrm{p}$ value $<0.05$.

\section{Results}

Out of 616 primigravidae, 113 (18.34\%) had abnormal GTT. The rest of the women were normal (503, $81.66 \%)$. There was not much difference in the demographic features except the age, where the non GDM women were slightly but significantly younger than the GDM group $(26.3 \pm 3.3$ versus $27.9 \pm 4.2 \mathrm{p}<0.001)$. There was a relatively higher percentage of Chinese and Indian women in the GDM group compared to the non GDM group (see Tab. 1).

Tab. 1: Patients' demographic data.

\begin{tabular}{|l|c|c|c|}
\hline Parameters & $\begin{array}{c}\text { GDM } \\
\mathrm{n}=113(\%)\end{array}$ & $\begin{array}{c}\text { NonGDM } \\
\mathrm{n}=503(\%)\end{array}$ & $\begin{array}{c}P \\
\text { value }\end{array}$ \\
\hline Race & $0.046^{\mathrm{a}}$ & & \\
\hline Malay & $73(64.6)$ & $362(72)$ & \\
\hline Chinese & $33(29.2)$ & $130(25.8)$ & \\
\hline Indian & $7(6.2)$ & $11(2.2)$ & \\
\hline Age (mean \pm SD & $27.9 \pm 4.2$ & $26.32 \pm 3.3$ & $<0.001^{\mathrm{b}}$ \\
\hline Weight (mean \pm SD) & $66.5 \pm 14.4$ & $60.3 \pm 12.2$ & $0.096^{\mathrm{b}}$ \\
\hline Working & $98(86.7)$ & $400(79.5)$ & $0.079^{\mathrm{a}}$ \\
\hline
\end{tabular}

${ }^{\text {aPearson }}$ Chi Square $\mathrm{P}$ value; ${ }^{\mathrm{b}}$ T-test $\mathrm{P}$ value

The GTT results revealed that the mean fasting and two hours postprandial blood glucose in the GDM group were significant $4.99 \pm 1.08 \mathrm{mmol} / 1$, and $8.86 \pm 1.41 \mathrm{mmol} / 1 \mathrm{re}-$ spectively compared to those of normal women ( $4.36 \pm 0.43$ $\mathrm{mmol} / 1$ and $5.71 \pm 1.11 \mathrm{mmol} / \mathrm{l})$. Our study also showed that family history of diabetes and maternal weight exceeding 80 $\mathrm{kg}$ (at the time of screening) were both significant risk factors for GDM (see Tab. 2). Antenatally there was no statistically significant difference in the incidence of complications including evidence of large for gestational age (LGA) fetus and proteinuria except for incidence of polyhydramnios ( $2.65 \%$ in GDM versus $0.2 \%$ in non GDM, $\mathrm{p}=0.028$ ).

Tab. 2: Risk Factors and antenatal features.

\begin{tabular}{|l|c|c|c|}
\hline & $\begin{array}{c}\text { GDM } \\
\mathrm{n}=113(\%)\end{array}$ & $\begin{array}{c}\text { NonGDM } \\
\mathrm{n}=503(\%)\end{array}$ & $\begin{array}{c}P \\
\text { value }\end{array}$ \\
\hline Risks & & & \\
\hline Abnormal MGTT & $113(18.34)$ & $503(81.66)$ & $0.635^{\mathrm{a}}$ \\
\hline $\begin{array}{l}\text { Fasting blood } \\
\text { glucose* }\end{array}$ & $4.99 \pm 1.08$ & $4.36 \pm 0.43$ & $<0.001^{\mathrm{b}}$ \\
\hline 2hr post prandial* & $8.86 \pm 1.41$ & $5.71 \pm 1.11$ & $<0.001^{\mathrm{b}}$ \\
\hline $\begin{array}{l}\text { Family h/o diabetes } \\
\text { mellitus }\end{array}$ & $56(49.56)$ & $182(36.18)$ & $0.008^{\mathrm{a}}$ \\
\hline Maternal wt $>80 \mathrm{Kg}$ & $24(21.24)$ & $40(7.95)$ & $<0.001^{\mathrm{a}}$ \\
\hline Antenatal features & & & \\
\hline LGA & $4(3.54)$ & $11(2.19)$ & $0.495^{\mathrm{c}}$ \\
\hline Polyhdromnion & $3(2.65)$ & $1(0.2)$ & $0.028^{\mathrm{c}}$ \\
\hline Glycosurea & $13(11.50)$ & $50(9.94)$ & $0.609^{\mathrm{a}}$ \\
\hline Protinurea & 0 & $8(1.59)$ & $0.362^{\mathrm{c}}$ \\
\hline
\end{tabular}

*(mean $\pm \mathrm{SD}) \mathrm{mmol} / \mathrm{l}$; ${ }^{\text {aPearson }}$ Chi Square P value; ${ }^{\text {b}}$ T-test $\mathrm{P}$ value; 'Fisher's exact test $\mathrm{P}$ value

Tab. 3: Maternal and neonatal complications.

\begin{tabular}{|l|c|c|c|}
\hline Features & $\begin{array}{c}\text { GDM } \\
\mathrm{n}=113(\%)\end{array}$ & $\begin{array}{c}\text { NonGDM } \\
\mathrm{n}=503(\%)\end{array}$ & $\begin{array}{c}P \\
\text { value }\end{array}$ \\
\hline Delivered & $111(98.2)$ & $437(86.88)$ & \\
\hline Missing data & $2(1.8)$ & $66(13.12)$ & \\
\hline Maternal & & & \\
\hline Premature delivery & $18(15.93)$ & $65(12.92)$ & $0.767^{\mathrm{a}}$ \\
\hline Pre-eclampsia & $2(1.77)$ & $17(3.38)$ & $0.391^{\mathrm{a}}$ \\
\hline Ceaserean section & $28(24.78)$ & $125(24.85)$ & $0.554^{\mathrm{a}}$ \\
\hline $\begin{array}{l}\text { Post partum } \\
\text { hemorrhage }\end{array}$ & 0 & 0 & - \\
\hline Fetal & & & \\
\hline$>$ 4kg & $6(5.31)$ & $9(1.79)$ & $0.094^{\mathrm{a}}$ \\
\hline Anomalies & 0 & 0 & - \\
\hline Neonatal death & 0 & 0 & - \\
\hline Apgar at 1 min & $8(7.08)$ & $9(1.79)$ & $0.933^{\mathrm{b}}$ \\
\hline Apgar at 5 min & $8(7.08)$ & $9(1.79)$ & $0.888^{\mathrm{b}}$ \\
\hline cord pH* & $7.24 \pm 0.2$ & $7.25 \pm 0.1$ & $0.467^{\mathrm{b}}$ \\
\hline Neonatal & & & \\
\hline Hypoglycaemia & $1(0.9)$ & $2(0.4)$ & $0.492^{\mathrm{a}}$ \\
\hline Hyperbilirubinaemia & $11(9.73)$ & $15(2.98)$ & $0.01^{\mathrm{a}}$ \\
\hline Hypocalcaemia & 0 & 0 & - \\
\hline Polycythaemia & 0 & 0 & - \\
\hline Birth trauma & $1(0.9)$ & $2(0.4)$ & $0.494^{\mathrm{a}}$ \\
\hline NICU admission & $5(4.42)$ & $30(5.96)$ & $0.514^{\mathrm{a}}$ \\
\hline
\end{tabular}

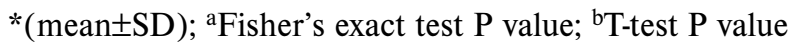


With regard to delivery details, two women were lost to follow up in the GDM group and 66 in the normal group. There was no statistically significant difference in terms of complications of pregnancy such as preterm delivery, preeclampsia or caesarean section (see Table 3) with no incidence of post partum hemorrhage during the period of study. Fetal outcome was also similar except for macrosomia which was seen more frequently among women with GDM although the difference was not significant.

In the neonatal period, significantly more offspring of GDM mothers developed jaundice compared to those of normal mothers $(9.73 \%$ versus $2.98 \%, p=0.01)$. Other neonatal complications were not statistically affected (Tab. 3).

\section{Discussions}

The prevalence of diabetes mellitus has increased globally with a higher incidence of GDM seen especially among Asian ethnics (7). In this study $18.34 \%$ of primigravidae were noted to have GDM as compared to an overall incidence of $24.9 \%$ irrespective of parity in a previous study at our centre (17). The previous study had also shown that maternal age of more than 35 years and family history of DM were significant risk factors for GDM. In the present study, GDM was detected even in a younger (27.9 \pm 4.2 years) age group of primigravidae (Tab. 1 ), similar to an observation among the blacks who are the higher risk ethnic group for GDM in the United States (7). This finding was in contrast to our earlier study in all parities which indicated the older age (17) of more than 35 years noted to be one of the risks to GDM.

The present study indicated family history of DM as a significant risk factor for GDM as seen in the present study as well as documented in previous (14). This highlights the importance of inherited (genetic) and lifestyle elements. Although this may not be the principal determinant to gestational hyperglycaemia, in a previous study this factor has been identified to be a more relevant risk to GDM in primigravidae than in multiparous women. Therefore genetic factors in GDM and its association with type 2 diabetes mellitus in later life as pointed out by other studies $(1,5,15)$ probably holds the explanation as to why even young primigravidae developed GDM that was seen in the present study.

Antenatal features of poorly controlled blood glucose such as uterus bigger than dates, proteinuria and glycosuria were not statistically significant in the GDM group despite a relatively high 2 HPPBG result $(8.86 \pm 1.41 \mathrm{mmol} / \mathrm{l})$. However, polyhydramnios which is a known complication of GDM (8) was a prominent feature in the current study although the actual number was very small (Tab. 2). Other maternal complications such as premature delivery, preeclampsia and caesarean section were not significantly increased in this study, most likely because of the relatively mild (FBG less than $5.30 \mathrm{mmol} / \mathrm{l}$ ) form of GDM which an- tenatally had been treated. Nevertheless studies (13) had advocated those with mild hyperglycemia during pregnancy would have higher risk of hypertensive disorders, preterm labor, cesarean delivery followed by metabolic and cardiovascular risks at later years.

Potential GDM complications are growingly evidenced in fetuses with macrosomia complicating delivery and respiratory distress. The babies from GDM mothers have long term increased risk of glucose intolerance, obesity, metabolic syndrome and younger Type 2 DM (13). This theoretically explains why younger aged primigravidae were diagnosed with GDM in current study. Nevertheless, over a long term assessment, there was no evidence of lower cognitive ability in children of diabetic mothers (18) whom had been exposed to higher concentration of glucose and fatty acids while in utero that perhaps had enhanced brain development.

There was no major neonatal complication although they (GDM group) were noted to have a higher percentage of macrosomic babies compared to the non-GDM (statistically was not significant) group (Table 3 ). A previous study (12) reported more macrosomic babies born to multiparous women with GDM compared to primigravidae which most likely explained the findings in the present study which comprised totally primigravidae. During the neonatal period no statistically significant complication was seen except for a higher incidence of hyperbilirubinaemia in the GDM group.

Recent studies $(4,11)$ have shown that treatment of mild GDM does not significantly reduce stillbirth and other neonatal complications but it has been seen to reduce the risk of fetal overgrowth, shoulder dystocia, caesarean delivery and hypertensive disorders. Therefore these studies $(4,11)$ have recommended treating mild GDM, although the exact timing of screening and initiating treatment has not yet been agreed upon. The benefits of treating mild GDM had been highlighted (10) after two recently conducted large-scale randomized trials. Perhaps this also could have been applied to our multiethnic population with mild GDM among primigravidae.

In conclusion, GDM in primigravidae was detected at a relatively young age with significantly more prevalent among those with maternal family history of DM, and maternal weight exceeding $80 \mathrm{Kg}$. Polyhydramnios and neonatal hyperbilirubinaemia were seen significantly more frequent in this group. Treating a mild degree of disease had led to no significant complications. Nevertheless for our centre, whether treating an already mild disease would not impose other major burden (ie including cost effectiveness), needs further evaluation.

\section{Acknowledgement}

This study was funded by the Fundamental grant of Universiti Kebangsaan Malaysia. The authors wish to thank all patients who participated in this study. 


\section{Conflict of interest}

The authors have no conflict of interest in conducting this study.

\section{References}

1. Aberg AE, Jonsson EK, Eskilsson I, Landin-Olsson M, Frid AH. Predictive fac tors of developing diabetes mellitus in women with gestational diabetes. Acta Obstet Gynecol Scand 2002; 81:11-16.

2. Agarwal MM, Hughes PF, Punnose J, Ezimokhai M, Thomas L. Gestational diabetes screening of a multi ethics, high risk population using glycated proteins Diabetes Res. Clin. Pract 2001; 51: 67-73.

3. Bevier WC, Jovanovic-Peterson L, Peterson CM. Diagnosis, management and outcome of gestational diabetes. Endocrinol. Metab. Clin. North Am 1995; 24 $103-138$

4. Bonomo M, Corica D, Mion E et al. Evaluating the therapeutic approach in pregnancies complicated by borderline glucose intolerance: a randomized clinica trial. Diabet Med. 2005; 22(11):1536-41

5. Cho YM, Kim TH, Lim S et al. Type 2 diabetes-associated genetic variant discovered in the recent genome-wide association studies are related to gestational diabetes mellitus in the Korean population. Diabetologia 2009; 52 253-261

6. Dornhost A, Paterson CM, Nicholls JSD et al. High prevalence of gestation diabetes in women from ethnic minority group. Diabetic Med 1992; 9:820-825

7. Getahun D, Nath C, Ananth CV, Chaves MR, Smuliah JC. Gestational diabete in the United States; Temporal trends 1989 through 2004. Am J Obstet Gynecol 2008, 198: 525.el-525.e5.
8. Keshavarz M, Cheung NW, Babaee GR, Moghadam HK, Ajami ME, Shariati M Gestational diabetes in Diabetes Res Clin Pract 2005; 69(3):279-86.

9. Krishnaveni GV, Hill JC, Veena SR et al. Gestational diabetes and the incidence of diabetes in the 5 years following the index pregnancy in South Indian Women. Diabetes Res.Clin.Pract 2007; 78:398-404.

10. Landon MB. Is there a benefit to the treatment of mild gestational diabetes mellitus? Am J Obstet Gynecol. 2010; 202(6):649-53.

11. Landon MB, Spong CY, Thom E et al. A multicenter, randomized trial of treat ment for mild gestational diabetes. N Engl J Med. 2009; 361(14):1339-48

12. Langer O, Yogev Y, Most O, Xenalis EMJ. Gestational diabetes: The consequences of not treating. Am J Obstet Gynecol 2005; 192: 989-97

13. Reece EA. The fetal and maternal consequences of gestational diabetes mellitus. J Matern Fetal Neonatal Med. $2010 ; 23(3): 199-203$

14. Retnakaran R, Connelly PW, Sermer M, Zinman B, Hanley AJ. The impact of family history of diabetes on risk factors for gestational diabetes. Clin Endocrino (Oxf). 2007:67(5):754-60.

15. Robitaille J, Grant AM. The genetics of gestational diabetes mellitus: evidence for relationship with type 2 diabetes mellitus. Genet. Med. 2008; 10(4): 240-250.

16. Santos-Ayarzagoitia M, Salina Martinez AM, Villarreal-Perez JZ. Gestational diabetes: Validity of ADA and WHO diagnostic criteria using NDDG as the reference test. Diabetes Res. Clin. Pract. 2007; 74:322-328

17. Shamsuddin K, Mahdy ZA, Siti Rafiaah I, Jamil MA, Rahimah MD. Risk factor screening for abnormal glucose tolerance in pregnancy. Int J Gynaecol Obstet 2001; 75(1):27-32.

18. Veena SR, Krishnaveni GV, Srinivasan K, Kurpad AV, Muthayya S, Hill JC et al. Childhood cognitive ability: relationship to gestational diabetes mellitus in Diabetologia. 2010; 53(10):2134-8

19. Veshiah V, Balaji V, Balaji NS et al. Gestational diabetes mellitus manifests in al trimesters of pregnancy. Diabetes Res. Clin. Pract 2007; 77:482-484

Received: 30/06/2010.

Accepted in revised form: 20/12/2010.

\section{Corresponding author:}

Dr M I Nor Azlin, Department of Obstetrics \& Gynaecology, Faculty of Medicine, University Kebangsaan Malaysia, Jalan Yaacob Latiff, 56000 Cheras, Kuala Lumpur, Malaysia; e-mail: azlinm@ppukm.ukm.my 